\title{
Effects of climate change on crop production in Cameroon
}

\author{
Munang Tingem ${ }^{1, *}$, Mike Rivington $^{2}$, Gianni Bellocchi ${ }^{3}$, Sayed Azam-Ali ${ }^{1}$, \\ Jeremy Colls ${ }^{1}$
}

\author{
${ }^{1}$ Agriculture \& Environmental Science Division, School of Biosciences, University of Nottingham, Nottingham NG7 2RD, UK \\ ${ }^{2}$ Macaulay Institute, Craigiebuckler, Aberdeen AB15 8QH, UK \\ ${ }^{3}$ Agrichiana Farming, Montepulciano, Italy
}

\begin{abstract}
This study involves an assessment of the potential effects of greenhouse gas climate change, as well as the direct fertilization effect of $\mathrm{CO}_{2}$ on crop yields in Cameroon. The methodology involves coupling the transient diagnostics of 2 atmosphere-ocean general circulation models, namely NASA/Goddard Institute GISS and the Hadley Centre's HadCM3, to the CropSyst crop model to simulate current and future $(2020,2080)$ crop yields (bambara nut, groundnut, maize, sorghum and soybean) in 8 agricultural regions of Cameroon. For the future we estimate substantial yield increases for bambara groundnut, soybean and groundnut, and little or no change and even decreases of maize and sorghum yields, varying according to the climate scenario and the agricultural region. Maize and sorghum (both C4 crops) yields are expected to decrease by 14.6 and $39.9 \%$, respectively, across the whole country under GISS 2080 scenarios. The results also show that the effect of temperature patterns on climate change is much more important than that of precipitation. Findings call for monitoring of climate change/variability and dissemination of information to farmers, to encourage adaptation to climate change.
\end{abstract}

KEY WORDS: Cameroon $\cdot$ Climate change $\cdot \mathrm{CO}_{2} \cdot$ Crop yields $\cdot$ Adaptation $\cdot$ CropSyst

\section{INTRODUCTION}

Agriculture is the mainstay of the Cameroonian economy. About $45 \%$ of Cameroon's gross domestic product originates from agriculture, with close to $80 \%$ of the labour force employed in this sector (CIA 2007). Most importantly, this sector is also responsible for providing food security to both the rural and urban populations from domestic production. However, this may not be true in the future. With a rapidly expanding population, the pressure on natural resources is mounting. Molua \& Utomakili (1998) noted that, due to population growth, low levels of input and equally low levels of government subsidies (e.g. quality seeds, fertilizers, pesticides and herbicides), per capita food production has been declining. This is worrisome and a real challenge for a government with a population of $\sim 17$ million people to feed. Worse still is the expected adverse impact of climate change on agriculture in the future, which may pose a further challenge to the country's food security.

Greenhouse gas (GHG)-induced climate change would very likely result in significant damage in the agricultural sector in sub-Saharan Africa, because the region already endures high heat and low precipitation (Slingo et al. 2005, Kurukulasuriya et al. 2006). The Third and Fourth Assessment Reports of the Intergovernmental Panel on Climate Change (IPCC) (Boko et al. 2007, Christensen et al. 2007) further urge that, even with the predicted climate change scenarios, extreme events (e.g. 1997 \& 2005 droughts in Cameroon) may still occur with devastating effects in more vulnerable areas, causing severe socioeconomic effects such as shortages of food and other essential basic commodities, as well as long-term food insecurity. 
Though a few studies have been conducted to assess the impact of climate change on agriculture in developing countries (Seo et al. 2005, Adejuwon, 2006, Thornton et al. 2006, Kabubo-Mariara \& Karanja 2007), there is a dearth of literature on this impact in Cameroon; thus the adaptation and mitigation measures that are available to policy makers are severely limited.

The present study aims to partially address this research gap. It uses the coupled climate scenariocrop model method, in which coupled atmosphereocean general circulation models (A-OGCMs), used to generate future climate scenarios, are integrated into crop models in order to simulate future crop yields (Tubiello et al. 2000, Brassard \& Singh 2007). The use of this method allows us to gain an insight not only into how future crop yields may change, but also into the nature of the factors responsible for yield changes, and how they may affect crop production. Understanding the impacts of long-term climate change on agriculture is crucial for future agricultural policies and interventions in Cameroon, as well as aiding practical steps to mitigate potentially adverse impacts of climate change, which is likely to have important implications for future food security.

The general objective of this study is to examine the effects of long-term climate change on Cameroon crop agriculture and identify the adaptation options of agroecological systems using a simulation analysis. The specific objectives are to simulate and highlight the expected effects of various long-term climate change scenarios on future agricultural productivity and discuss policy design, research and extension in planning potentially effective adaptation options to mitigate negative climate change impacts.

\section{CLIMATE AND AGRICULTURE IN CAMEROON}

Cameroon covers an area of about $475440 \mathrm{~km}^{2}$ between 2 and $13^{\circ} \mathrm{N}$ and is among the 52 countries that comprise sub-Saharan Africa. It is ranked 172 out of 229 countries in the world in terms of per capita income, and nearly $40 \%$ of the population (6.8 million people) live on $<\mathrm{US} \$ 2 \mathrm{~d}^{-1}$ (World Bank 2007). Most agriculture is practised at the subsistence scale by local farmers using simple tools. The majority of the country's poor live in rural areas and rely on agriculture and other natural resources for their living.

The area is characterized by highly contrasting physical features, including $402 \mathrm{~km}$ of coastline and mountain ranges punctuated by peaks of $>3000 \mathrm{~m}$. Climate characteristics, reflecting the topography and latitudinal range, roughly follow a north-south gradi- ent, with the humid equatorial region in the south and semi-arid regions to the north. The equatorial zone stretches from 2 to $6^{\circ} \mathrm{N}$, covering the southern and the mountainous western part of the country. Its climate corresponds to the classical Guinean region, with the following subtypes: (1) the seaboard, e.g. Kribi and Tiko with abundant rainfall (2634 and $3198 \mathrm{~mm} \mathrm{yr}^{-1}$, respectively); (2) inland areas, e.g. Yaounde, with total rainfall $<1660 \mathrm{~mm} \mathrm{yr}^{-1}$ (this climate subtype prevails over the southern part of the southern Cameroon plateau, extending into the east of the country around Batouri); and (3) north of $6^{\circ} \mathrm{N}$ (the Sudanese-Sahelian subtype differs from the 'inland' with total rainfall decreasing from 1513 to $834 \mathrm{~mm} \mathrm{yr}^{-1}$ ). Annual average temperature across the country varies between 20 and $29^{\circ} \mathrm{C}$, and in the extreme north daily temperatures are usually between 25 and $34^{\circ} \mathrm{C}$.

The humid equatorial zone in the south favours the cultivation of cash crops such as oil palm, bananas, cocoa, rubber, plantains and coffee, and the key food crops are maize Zea mays L., groundnut Arachis hypogaea L., sorghum Sorghum bicolour (L.), bambara groundnut Vigna subterranea L. Verdc and soybean Glycine max (L.) Merr. The semi-arid region to the north mostly favours the growth of millet, sorghum, maize and groundnuts. Growing season is related to the rainy season, and planting is fine tuned to very specific times of the year. In the equatorial zone comprising Bamenda, Batouri, Kribi, Tiko and Yaounde, there are 2 rainy seasons: the first is the 'long season', from March to July with planting in March, and the second is the 'short season', from August to November. In the tropical zone (Garoua, Maroua and Ngaoundere) there is only 1 rainy season, from May to October, and planting starts in May (Ndemah 1999). Table 1 shows the geo-location of the study sites, chosen to represent the variety of agricultural landscapes in Cameroon.

Table 1. Geo-references of the 8 agricultural study sites along with annual rainfall data

\begin{tabular}{|lrrrc|}
\hline Site & $\begin{array}{c}\text { Latitude } \\
\left({ }^{\circ} \mathrm{N}\right)\end{array}$ & $\begin{array}{c}\text { Longitude } \\
\left({ }^{\circ} \mathrm{E}\right)\end{array}$ & $\begin{array}{c}\text { Elevation } \\
(\mathrm{m})\end{array}$ & $\begin{array}{c}\text { Rainfall } \\
(\mathrm{mm})\end{array}$ \\
\hline Bamenda & 6.05 & 10.10 & 1239 & 2378 \\
Batouri & 4.47 & 14.37 & 656 & 1499 \\
Garoua & 9.33 & 13.38 & 244 & 1090 \\
Kribi & 2.95 & 9.89 & 16 & 2634 \\
Maroua & 10.44 & 14.25 & 422 & 834 \\
Ngaoundere & 7.34 & 13.57 & 1104 & 1514 \\
Tiko & 4.08 & 9.37 & 52 & 3198 \\
Yaounde & 3.83 & 11.51 & 760 & 1655 \\
& & & & \\
\hline
\end{tabular}




\section{METHODS AND DATA}

The study uses the coupled climate scenario-crop model approach in which present and future climate conditions, generated by the selected climate models following 2 GHG emission scenarios, are integrated as inputs into the crop model so as to simulate crop growth, development and production. The 'naive farmer' scenario is used, meaning that all variables other than weather and atmospheric $\mathrm{CO}_{2}$ concentration, namely soil, cultivar and management characteristics, are held constant between present and future crop yield simulations. Though in reality farmers are able to make management changes to cope with an altered climate, representing the diversity of these adaptations within a modelling project was seen as adding an additional level of complexity to a study primarily aimed at determining the impacts of the climate on crop production.

Present and future crop yields are compared to evaluate the impacts of GHG-induced climate change on agriculture. The A-OGCM climate models used in this study are the coupled NASA/Goddard Institute GISS and HadCM3 of the British Hadley Centre. Both models are forced by the SRES A2 and B2 emission scenarios (Houghton et al. 2001). The selection of AOGCMs was based on the general quality and reliability of the simulated current climate compared to observed data and data availability to generate baseline (1961 to 1990) and future climate scenarios (2020s, 2080s) (Brassard 2003, Brassard \& Singh 2007). The crop model used, CropSyst (Stöckle et al. 2003), was selected for its robustness and relatively easy applicability with commonly available information (Rivington et al. 2007, Moriondo et al. 2007, Tingem et al. 2008).

The study regions were chosen based on the desire to have as complete a representation as possible of the agricultural landscape of Cameroon. Crop yields and changes were evaluated for 5 different crops, namely: maize, sorghum, groundnut, bambara groundnut and soybeans. The choice of these crops is based on the availability of observed yield data for validation purposes, the relative importance of these crops to the subsistence farmer, and the desire to have a diverse and representative view of crop production potential in Cameroon. Representative soil properties (thickness and texture) for each of the simulation points were extracted from the International Soil Reference and Information Center database (www.isric.nl; Batjes 1995). Available agro-data (e.g. yield, phenological parameters) was obtained from the Central Bureau of Statistics' published district reports in the study areas (Agristat 2001).

\subsection{Weather data and climate scenarios}

Daily observed maximum temperature $\left(\mathrm{T}_{\max }\right)$, minimum temperature $\left(T_{\min }\right)$ and rainfall data from 1979 to 2003 were obtained from the University Cooperation for Atmospheric Research (UCAR) (http://dss.ucar. edu/datasets) for each of the 8 sites used in the study. For each region, the precipitation, $\mathrm{T}_{\max }$ and $\mathrm{T}_{\min }$ data from 1 of the major weather stations was chosen as representative of the climate of that region (1 station per region). Solar radiation $\left(S_{0}\right)$ data was not available. However, $S_{\mathrm{o}}$ is a key input into crop models and can be a major source of error in yield estimates (Rivington et al. 2005). So as to avoid the risk of introducing additional uncertainty between scenarios in estimating $S_{0}$ we used functions within the CropSyst crop model, based on air temperature for each scenario, to make estimates. Availability of $S_{\mathrm{o}}$ data remains a problematic issue for crop modelling and climate change impacts, but this approach ensures that any uncertainties in $S_{\mathrm{o}}$ data remain constant between the compared scenarios.

Since we are evaluating long-term effects of climate change and variability on crop yields, it was necessary to expand the temporal range of the weather data for use in the crop model so as to allow a good estimation of the probability of extreme events. We used the ClimGen software (Version 4.1.05; www.bsyse.wsu. edu/climgen/) to produce generated climatic data to supplement the 1979 to 2003 UCAR data. The model requires inputs of daily series of weather variables (precipitation, $\mathrm{T}_{\max }$ and $\mathrm{T}_{\min }$ ) to calculate parameters used in the generation process for any length of period at a location of interest. Further information on ClimGen is well documented elsewhere (Stöckle et al. 2003).

According to Richardson (2000), long-term data records are needed, at least $10 \mathrm{yr}$ of weather data for estimation of temperature parameters and 20 or more years for estimation of precipitation parameters, to obtain stable representative estimates. Thus, we used the UCAR observed $25 \mathrm{yr}$ historic daily records of temperature and precipitation, to generate a further $25 \mathrm{yr}$ of modelled daily weather data to extend the coverage to $50 \mathrm{yr}$ (baseline scenario) for each location. Statistics using $t$ - and $F$-tests ( 0.05 significance level) to compare the differences between generated and observed weather data indicated that there was no significant difference between generated values and observed data; thus, representative long-term weather data of precipitation and temperatures could, in general, be generated from historical weather data using Clim Gen. Table 2 summarises the outcome of the series of statistical comparisons for all the test sites. Further evidence of model performance was obtained by compar- 
Table 2. Comparisons of observed precipitation $(\mathrm{mm})$ and maximum temperature $\left(\mathrm{T}_{\max },{ }^{\circ} \mathrm{C}\right)$ means and variances with those of 25 yr data generated by ClimGen at 8 sites. Probability levels (p) calculated by $t$ - and F-tests for monthly means and variance; $p>0.05(5 \%)$ indicates that the null hypothesis of equality between observed and simulated data cannot be rejected

\begin{tabular}{|c|c|c|c|c|c|c|c|c|c|c|c|c|}
\hline \multirow{3}{*}{ Location } & \multicolumn{6}{|c|}{ Precipitation -} & \multicolumn{6}{|c|}{$\longrightarrow \mathrm{T}_{\max }$} \\
\hline & \multicolumn{2}{|c|}{ Observed } & \multicolumn{2}{|c|}{ Generated } & \multicolumn{2}{|c|}{$\mathrm{p}$} & \multirow{2}{*}{\multicolumn{2}{|c|}{$\begin{array}{c}\text { Observed } \\
\text { Mean Variance }\end{array}$}} & \multirow{2}{*}{\multicolumn{2}{|c|}{$\begin{array}{c}\text { Generated } \\
\text { Mean Variance }\end{array}$}} & \multicolumn{2}{|c|}{$\mathrm{p}$} \\
\hline & Mean & Variance & Mean & Variance & $t$-test & $F$-test & & & & & $t$-test & $F$-test \\
\hline Bamenda & 195.8 & 25185 & 176.1 & 11202.4 & 0.724 & 0.097 & 23.8 & 2.93 & 24.7 & 2.96 & 0.188 & 0.493 \\
\hline Batouri & 123.2 & 5375.9 & 134.7 & 8506.1 & 0.74 & 0.229 & 29.6 & 2.5 & 29.1 & 3.35 & 0.457 & 0.318 \\
\hline Garoua & 83.1 & 8425.6 & 88.3 & 7600.7 & 0.888 & 0.434 & 34.9 & 9.27 & 34.3 & 8.89 & 0.617 & 0.473 \\
\hline Kribi & 219.5 & 22020 & 226.6 & 19342.7 & 0.838 & 0.417 & 30.0 & 2.05 & 30 & 2 & 0.933 & 0.484 \\
\hline Maroua & 65.9 & 6842.8 & 72.3 & 7646.4 & 0.854 & 0.429 & 34.5 & 8.81 & 33.5 & 8.08 & 0.447 & 0.445 \\
\hline Ngaoundere & 124.7 & 12638 & 126.1 & 11874.9 & 0.976 & 0.46 & 29.0 & 4.0 & 28.1 & 3.83 & 0.287 & 0.472 \\
\hline Tiko & 266.5 & 38782.2 & 260.3 & 41799.1 & 0.94 & 0.452 & 30.0 & 3.25 & 30.1 & 3.3 & 0.937 & 0.49 \\
\hline Yaounde & 135.7 & 8083 & 153.6 & 7593.5 & 0.624 & 0.46 & 28.4 & 2.47 & 27.8 & 2.33 & 0.329 & 0.463 \\
\hline
\end{tabular}

ing observed and generated precipitation $\mathrm{T}_{\max }$ in Ngaoundere, Tiko and Kribi using exceedence probability graphs (Fig. 1). These probabilities of exceedence plots are an important indicator of model performance, in that they show when the model is able to produce estimates that reproduce the probability of event magnitudes occurring, in this case, the mean monthly precipitation and $\mathrm{T}_{\max }$. The findings show that ClimGen is capable of producing good quality estimates across the range of spatial scales and climatic zones found within Cameroon. Further information on the assessment of the ClimGen stochastic weather generator at Cameroon sites is well documented in Tingem et al. (2007).

The impact of climate change on agricultural production was assessed using the observed baseline data and the adjusted A-OGCM-simulated future (2020s, 2080s) climate scenarios from GISS and HadCM3. The GISS model of the NASA/Goddard Institute for Space Studies is described by Hansen et al. (1998). A description of the HadCM3 model is given by Johns et al. (2003). The models differ in how they represent the effects of climate processes. Horizontal grid resolution is $4 \times 5^{\circ}$ (latitude $\times$ longitude) for GISS and $2.5 \times 3.75^{\circ}$ for HadCM3.

We generated 8 climate change scenarios at each site using the standard scenario generation methodology as discussed in ANL (1994), USCP (1994) and Rosenzweig \& Tubiello (1997). Atmospheric $\mathrm{CO}_{2}$ concentrations were specified for each period according to the 'business as usual' IPCC scenario, the medium-

Fig. 1. Exceedence probability functions for the distribution of monthly mean precipitation for the observed (Obs) and generated (Gen) data by ClimGen: (a) monthly mean precipitation in Ngaoundere, (b) monthly mean precipitation in Tiko and (c) exceedence probability functions of monthly $\mathrm{T}_{\max }$ for observed and synthetically generated data for Kribi
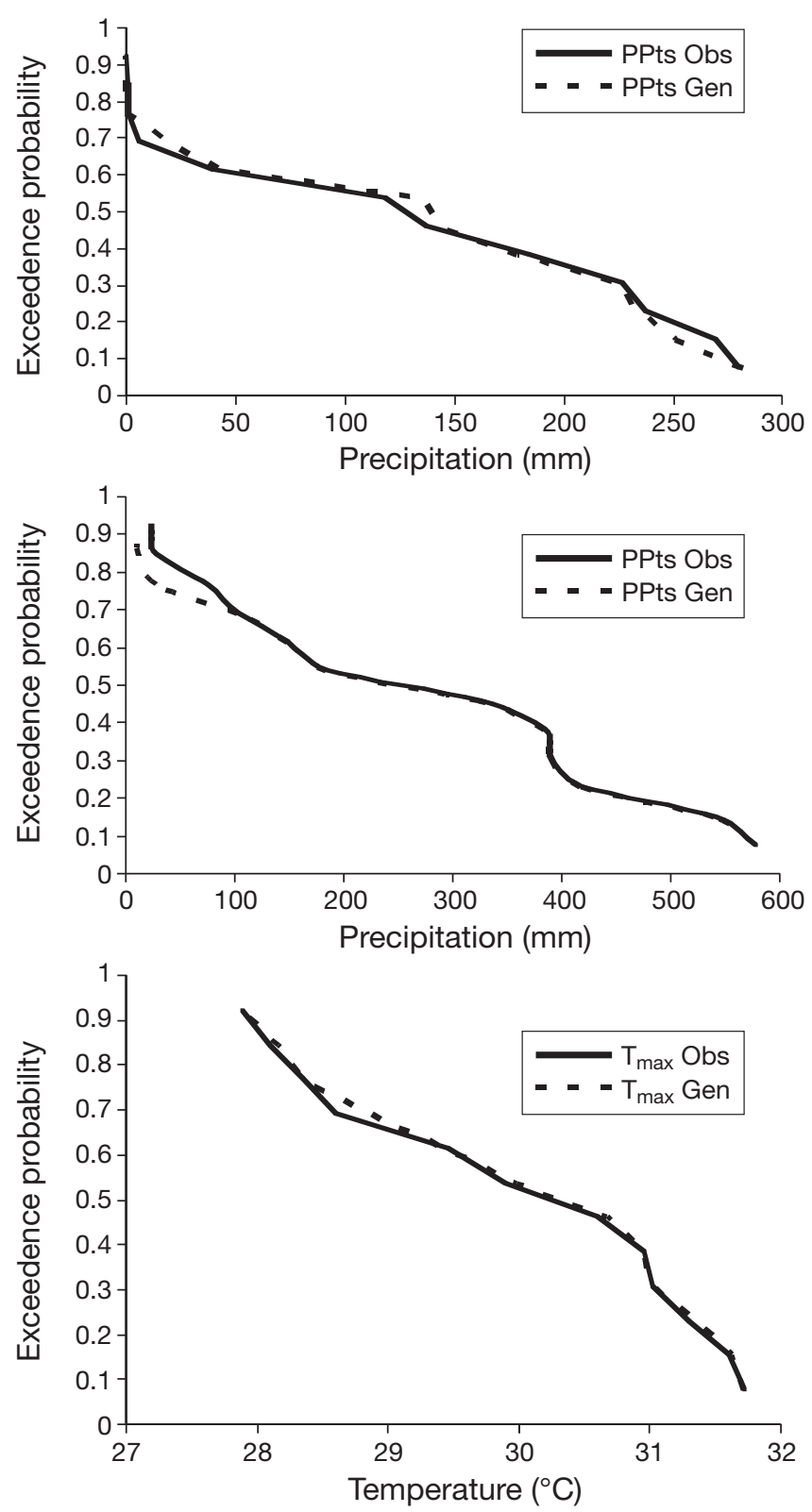
high emission scenario A2, and its more optimistic medium-low counterpart B2 (Houghton et al. 2001).

Scenarios of climate change were created by taking the difference between transient GCM (general circulation model) runs with current climate data from the 30 yr baseline climate period, the baseline temperatures were adjusted by adding the change in temperature and the baseline daily precipitations were adjusted by multiplying ratio changes in precipitation suggested by transient GCM runs (ANL 1994). In this way, new 50 yr long climatological time series were generated for each scenario at each location, providing a broad range of conditions that mirror variability and capture a range of uncertainties as described by the IPCC. Table 3 summarises climate change as projected by the 8 A-OGM scenarios across Cameroon.

\subsection{Crop growth model}

The CropSyst model is a multi-year, multi-crop, daily time step cropping system simulation model. The model has been applied and used extensively to simulate crop growth and yield for a range of crops such as wheat, maize, soybean, sorghum, groundnut and forage crops in diverse environments. It has been used in detailed studies for tropical crops and has been shown to be robust and accurate for a diverse range of local environments, including those found within Cameroon (Tingem et al. 2008). It is considered a well-balanced crop simulator, simulating different crops from a common set of parameters.

The model simulates the soil water budget, the soil-plant nitrogen budget, the crop canopy and root growth, crop phenology, dry matter production, yield, residue production and decomposition, and erosion. The main weather variable inputs are daily precipita-

Table 3. Changes in the climate variables between baseline and future climate as predicted by the 8 general circulation model scenarios. A2 and B2: medium-high and medium-low emission scenario, respectively

\begin{tabular}{|lrccc|}
\hline Scenario & & $\begin{array}{c}\Delta \mathrm{CO}_{2} \\
(\mathrm{ppm})\end{array}$ & $\begin{array}{c}\Delta \text { Precipi- } \\
\text { tation }(\%)\end{array}$ & $\begin{array}{c}\Delta \text { Mean tem- } \\
\text { perature }\left({ }^{\circ} \mathrm{C}\right)\end{array}$ \\
\hline GISS & A2 2020 & 415 & -3.7 & 1.6 \\
& 2080 & 677 & 1.1 & 4.4 \\
& B2 2020 & 411 & -2.2 & 1.4 \\
HadCM3 & A2 2080 & 548 & -1.5 & 3.1 \\
& 2020 & 415 & 0.8 & 0.7 \\
& B2 2080 & 677 & 4.5 & 3.5 \\
& 2080 & 411 & 4.1 & 0.8 \\
& 2020 & 548 & 2.5 \\
\hline
\end{tabular}

tion, $\mathrm{T}_{\max }$ and $\mathrm{T}_{\min } . S_{\mathrm{o}}$ is estimated by CropSyst, based on values of air temperature. The model allows the user to specify management parameters such as sowing date, cultivar genetic coefficients (e.g. photoperiodic sensitivity, duration of grain filling, maximum leaf area index [LAI]), soil profile properties (soil texture, thickness, water and initial nitrogen content), fertilizer and irrigation management, tillage, etc. Crop growth is simulated for the whole canopy by calculating unstressed (potential) biomass based on crop potential transpiration and on crop intercepted photosynthetically active radiation. This potential growth is then corrected by any water and nitrogen limitations, to determine actual daily biomass gain. The simulated yield is then obtained as the ratio between actual total biomass accumulated at physiological maturity and crop-specific harvest index (harvestable yield/aboveground biomass).

The simulation of crop development is based on the timing of the important development stages (thermal time) calculated as growing degree days (GDD) accumulated throughout the growing season (starting from planting until harvest). Average air temperature above a base and below a cut-off temperature is considered for GDD calculations. The accumulation of thermal time may be accelerated by water stress.

Water balance processes in CropSyst include rainfall, runoff, and interception by the crop canopy and residues, infiltration, redistribution in the soil profile, crop transpiration and soil evaporation. Potential evaporation is estimated by the PriestleyTaylor method (Priestley \& Taylor 1972). Water dynamics in the soil is handled by a Richard's equation, which is solved numerically using the finite difference technique.

CropSyst has data requirements that can be reasonably met and provides support utilities to substitute for missing parameters based on well-established procedures (e.g. using pedo-transfer functions to derive soil hydraulic parameters). Hence, it provides a conceptually unified modelling system for many crops, minimizing the dangers of structural uncertainty in making both cross-crop and inter-spatial comparisons (Rivington et al. 2007). As such, it is able to represent well the variation in yield determined by weather-driven environmental conditions and respond to specific management regimen.

Values were assigned to crop parameters based on typical values from the CropSyst user manual and from the authors' own experience. A number of parameters accounting for cultivar-specific differences were calibrated based on outputs of development and growth characteristics. Further parameterization was achieved by minimization of differences between actual and simulated yields for a limited num- 
ber of simulation trials using available fieldreported data (Agristat 2001). Remaining parameters were adjusted within a reasonable range as provided by the manual. The calibration of the phenological parameters (e.g. GDD) was made using data provided by the Institute of Agricultural Research (IRA-Cameroon).

Simulations were run with sowing dates set to 15 March, corresponding to Day 74 of the year (DOY), in Bamenda, Batouri, Kribi, Tiko and Yaounde. In Garoua, Maroua and Ngaoundere, the sowing date was set to 15 May (DOY 135), which agrees with traditional crop management in the zones (Ndemah 1999) for all crops. A $1 \mathrm{~m}$ soil depth was considered to simulate the soil water balance, because it corresponds to the observed maximum crop root length (Farre 1998). The finite difference soil water balance function, by which water moves up and down depending on the soil water potential of vertically adjacent layers, was used for the redistribution of water in the soil under non-limiting soil fertility. An implementation of the Priestley-Taylor equation (Priestley \& Taylor 1972), based on air temperature and $S_{\mathrm{o}}$ inputs, was used to compute the reference evapotranspiration. Of the crop residue, $40 \%$ was assumed to remain in the field after harvest for recycling purposes (Abraha \& Savage 2006). No irrigation was used as this is not a common practice.

\subsection{Crop model and ClimGen validation}

Validation of the simulated crop yields was limited by the availability of observed yield data. Basic tests were conducted in order to verify the applicability of the CropSyst crop model to the selected agricultural regions, and to evaluate the reliability of its results. This was done by comparing, for the different crops and agricultural regions, the averages of the simulated and observed (Agristat 2001) yields for each crop at each region across Cameroon. The results, presented in Table 4, are expressed as the percentage difference between average simulated and observed yields. According to Ritchie et al. (1998) and Brassard (2003), a difference between observed and simulated yields of up to $\pm 15 \%$ is judged acceptable. As seen in Table 4, for all crops and regions, the validation results are within this range; hence, the model can be seen as robust under the diverse range of environmental conditions found within Cameroon. More detailed evaluation of maize estimates by the model are available in Tingem et al. (2008).

Statistical tests ( $t$ - and $F$-tests) to compare the differences between generated and observed weather data indicated there was no significant difference between generated values and observed data (significance level $<0.05)$; thus, representative long-term weather data on precipitation and temperature could, in general, be generated from historical weather data using Clim Gen (Tingem et al. 2007). This finding has particular relevance for agricultural modelling applications in Cameroon where there are limited observational records, making it difficult to evaluate long-term effects of weather on crop yield.

\subsection{Projection analyses}

The effects of a $\mathrm{CO}_{2}$-induced climate change on crop production, expressed as the relative changes in yields between baseline and future (2020s/2080s) climate are presented as percentage changes in average yields from the baseline. In order to assess the strength of $\mathrm{CO}_{2}$ effects on crop yield, as indicated by Tubiello et al. (2000), simulations were also run without incorporating the change in atmospheric $\mathrm{CO}_{2}$ levels.

The yields and phenological maturity dates simulated under the alternative climate scenarios were compared using exceedence probability $\left(P_{\mathrm{e}}, \%\right)$ distributions, following Weibull (1961):

$$
P_{\mathrm{e}}=\frac{m}{n+1}
$$

where $m$ is the rank order of each yield estimate, with $m=1$ as the largest and $m=n$ as the lowest, with $n$ being the number of observations. The coefficient of variation $(\mathrm{CV})$ values of yield, defined as the ratio of standard deviation to the mean, were computed over the entire time series available at each site. The \%CV represents a measure of the farmer's risk, low CVs indicate stable year-to-year production, while high CVs denote high inter-annual variability (Rosenzweig \& Tubiello 2007). 


\section{RESULTS}

\subsection{Climate change analyses}

The GCM runs were for 2 time periods: the 2020s, representing the period from 2010 to 2039, and the 2080s, representing the period from 2070 to 2099. According to these runs, annual temperatures in the selected regions across the country are expected to rise by 0.7 to $0.8^{\circ} \mathrm{C}$, according to HadCM3, with respect to the baseline, in the 2020s. Alternatively, the GISS projects a 1.4 to $1.6^{\circ} \mathrm{C}$ increase in the same time period. Annual temperatures in the 2080 s are projected to increase relative to the baseline by 2.5 to $3.5^{\circ} \mathrm{C}$ and 3.1 to $4.4^{\circ} \mathrm{C}$ according to the HadCM3 and GISS GCMs, respectively.

Precipitation is expected to increase or decrease depending on the GCM used. For the GISS and HadCM3 average percent changes in precipitation ranged from -3.7 to $1.1 \%$ and from 0.8 to $5.2 \%$, respectively. However, the GISS model projected a decreasing trend of precipitation in the 2020s and 2080s for most of the study sites (Table 3). The HadCM3 model simulated an increasing trend in precipitation across all scenarios.

\subsection{Crop yield changes under alternative climate scenarios}

Relative changes in the average yields of maize, sorghum, bambara groundnut, groundnut and soybean predicted between present (baseline) and future (2020s/2080s) climates are presented in Table 5.

\subsubsection{Maize}

Nearly all future climate scenarios show a general tendency towards diminishing future maize yields in all agricultural regions; ranging between +27.1 and $-69.6 \%$ (Table 5). At Bamenda both scenarios predict grain yield to decrease by 5.9 to $24.7 \%$ in the $2020 \mathrm{~s}$ and by 20.6 to $69.6 \%$ in the 2080s. The CV of yield (Table 6) consistently increased in the early and latter parts of the 21st century at Bamenda, Batouri and Garoua, suggesting increased risk to farmers.

The exceptions for both GISS and HadCM3 simulations were Ngaoundere and Kribi agricultural regions, where yield increased by 6.2 to $27.1 \%$ and 9.6 to $25.9 \%$, respectively, with decreased yearto-year variation. This was due to a relatively low projected increase in air temperatures during the grain-filling periods in Ngaoundere (July) and Kribi (May). The decrease in the duration for the regular crop-growing season for maize in the near future was simulated at between 2 and $11 \mathrm{~d}$ for A2 and B2 scenarios, respectively, and at approximately 5 to $26 \mathrm{~d}$ in the last 3 decades of the century, compared to growing season length under current climatic conditions (Fig. 2). The greatest decrease across all the scenarios was recorded in Bamenda $(69.6 \%$ decrease) under GISS A2 2080, and the highest yield was at Ngaoundere $(27.1 \%$ increase) under HadCM3 A2 2020s (Table 5). Taking the mean overall regions, yield oscillated between -14.6 and $8.1 \%$ for GISS and between -8.2 and $15.7 \%$ for the HadCM3 model.

\subsubsection{Sorghum}

The sorghum results appear to indicate that, with the exception of the HadCM3 A2 \& B2 2020s data, $\mathrm{CO}_{2}$-induced climate change will result in either a substantial decrease or no change on sorghum crop yield, variable with location and scenario. Changes in yield (Table 5) follow 2 patterns. Firstly, continuous decreases in yield are projected under A2 and B2 emission scenarios for both GISS and HadCM3, in the latter part of this century. This is the pattern expected at Garoua, Maroua and Ngaoundere, which represent the Sahelian eco-climatological zones in which these crops are grown. Secondly, a slight reduction in yields is recorded for both GCMs and emission scenarios in the 2020s period. Sizable gains occur in Maroua (+17.1 and 14.6\%) under HadCM3 A2 \& B2 2020, respectively. The 2080 simulations exhibit a 9.3 to $63.8 \%$ drop in yields, with the larger reduction occurring in Ngaoundere under GISS A2 $2080(-63.8 \%)$ and increased CVs across all scenarios. The smallest effects on yields were simulated under HadCM3 A2 2020 at all locations. Change in number of days from emergence to crop maturity ranged from 2 to $29 \mathrm{~d}$, with the greatest reduction recorded at Ngaoundere.

\subsubsection{Groundnut}

Projections indicate substantial increases in the yield of groundnut by 21.5 to $109 \%$ from the baseline, across all scenarios in Batouri, Kribi, Maroua, Ngaoundere and Tiko, with reduced CVs. Simulated production in Bamenda decreased across all scenarios by 11.9 to $41.6 \%$, except for HadCM3 A2 \& B2 2020, where yields increased by $1.9 \%$. Scenario A2 2080s for both GCMs produced a drop in yields at Garoua and Yaounde by 1.2 to $12.4 \%$. The growing season was shortened by 2 to $6 \mathrm{~d}$. 
Table 5. Relative change (\%) in yields $\left(\mathrm{kg} \mathrm{ha}^{-1}\right)$ between baseline and future climate, as predicted by the 8 climate scenarios for 5 crops studied

\begin{tabular}{|c|c|c|c|c|c|c|c|c|c|}
\hline \multirow{2}{*}{ Location } & \multirow{2}{*}{ Baseline } & \multicolumn{4}{|c|}{ GISS } & \multicolumn{4}{|c|}{ HadCM3 } \\
\hline & & A2 2020 & A2 2080 & B2 2020 & B2 2080 & A2 2020 & A2 2080 & B2 2020 & B2 2080 \\
\hline \multicolumn{10}{|l|}{ Maize } \\
\hline Bamenda & 1294 & -24.7 & -69.6 & -22.9 & -51.2 & -6.7 & -56.2 & -5.9 & -20.6 \\
\hline Batouri & 1488 & 0.9 & -33 & 0.2 & -17.8 & 13.6 & -22.5 & 14.2 & -8.2 \\
\hline Garoua & 1945 & 3.1 & -16.1 & 4.1 & -11 & 9.1 & -12.1 & 11.2 & -6.4 \\
\hline Kribi & 1835 & 18.9 & 9.6 & 19.4 & 13.1 & 25.4 & 12.3 & 25.9 & 15.3 \\
\hline Maroua & 2171 & 5.3 & -10.5 & 6.9 & -6.6 & 13.3 & -8.1 & 10.6 & -2.91 \\
\hline Ngaoundere & 2318 & 24.6 & 6.2 & 25 & 17.3 & 27.1 & 13.8 & 26.9 & 22 \\
\hline Tiko & 2447 & 12.6 & -0.6 & 12.5 & 3.5 & 18.3 & 3.4 & 18.4 & 7.6 \\
\hline Yaounde & 2158 & 18.4 & -2.7 & 20 & 7.8 & 24.1 & 3.5 & 24.1 & 12.3 \\
\hline Mean & 1957 & 7.4 & -14.6 & 8.2 & -5.6 & 15.5 & -8.2 & 15.7 & 2.4 \\
\hline \multicolumn{10}{|l|}{ Groundnut } \\
\hline Bamenda & 1017 & -13.5 & -41.6 & -11.9 & -30.1 & 1.9 & -33.4 & 1.9 & -22.7 \\
\hline Batouri & 996 & 38.4 & 21.9 & 30.4 & 30.0 & 51.3 & 47.1 & 57.8 & 50.6 \\
\hline Garoua & 995 & 15.7 & -7.4 & 16.9 & 0.6 & 19.8 & -1.2 & 23.2 & 6.6 \\
\hline Kribi & 557 & 109.0 & 113.0 & 109.0 & 108.7 & 110.0 & 108.7 & 109.2 & 108.9 \\
\hline Maroua & 1172 & 45.3 & 34.5 & 46 & 38.2 & 48.9 & 36.6 & 48 & 40.7 \\
\hline Ngaoundere & 1197 & 50.3 & 37.2 & 51 & 41.7 & 57.2 & 40.1 & 57.1 & 44.5 \\
\hline Tiko & 948 & 19 & -1.8 & 25.6 & 12.1 & 35.2 & 16.8 & 32.3 & 21.5 \\
\hline Yaounde & 1106 & 8.1 & -12.4 & 11.1 & -2.8 & 18.6 & -6.3 & 18.6 & 1.8 \\
\hline Mean & 998 & 34.0 & 17.9 & 34.8 & 24.8 & 42.9 & 26.1 & 43.5 & 31.5 \\
\hline \multicolumn{10}{|l|}{ Bambara } \\
\hline Bamenda & 1160 & 31.2 & 1.2 & 32.9 & 17.3 & 42.5 & 13.2 & 43.3 & 23.5 \\
\hline Garoua & 1402 & 24.3 & 4.9 & 25.2 & 11.9 & 31 & 10.2 & 30.1 & 16.8 \\
\hline Maroua & 1310 & 37.2 & 25.9 & 37.8 & 29.5 & 41.3 & 28.2 & 40.4 & 32.1 \\
\hline Ngaoundere & 1571 & 52.5 & 46.8 & 53.4 & 49.1 & 58.3 & 48.7 & 57.1 & 50.5 \\
\hline Tiko & 1184 & 9.3 & -5.1 & 2 & 6.4 & 20.5 & 12.5 & 28.2 & 11.2 \\
\hline Yaounde & 1193 & 21.5 & 3.9 & 24.6 & 12.8 & 31.6 & 9.6 & 31.6 & 16.8 \\
\hline Mean & 1303 & 29.3 & 12.9 & 29.3 & 21.2 & 37.5 & 20.4 & 38.5 & 25.2 \\
\hline \multicolumn{10}{|l|}{ Sorghum } \\
\hline Garoua & 1311 & -8.2 & -35.7 & -6.1 & -28.5 & 1.3 & -32 & 4.4 & -21.9 \\
\hline Maroua & 1484 & 3.2 & -20.1 & 6.3 & -14.2 & 17.1 & -16.2 & 14.6 & -9.3 \\
\hline Ngaoundere & 1280 & -16.6 & -63.8 & -12.3 & -47.8 & 3.8 & -53.5 & 3.4 & -40.7 \\
\hline Mean & 1358 & -7.2 & -39.9 & -4.0 & -30.2 & 7.4 & -33.9 & 7.5 & -24.0 \\
\hline \multicolumn{10}{|l|}{ Soybean } \\
\hline Bamenda & 572 & 57.6 & 27.9 & 58.5 & 38.8 & 68.7 & 34.2 & 78.9 & 45.5 \\
\hline Ngaoundere & 1169 & 27.9 & 5.5 & 29.6 & 12.6 & 39.5 & 10.9 & 39.5 & 18.8 \\
\hline Tiko & 110 & 126.9 & 130.4 & 127.7 & 134 & 153.6 & 148.2 & 145.5 & 162.4 \\
\hline Mean & 617 & 70.8 & 54.6 & 71.9 & 61.8 & 87.3 & 64.4 & 88.0 & 75.6 \\
\hline
\end{tabular}

\subsubsection{Bambara groundnut}

Bambara groundnut showed gains across all scenarios, except for Tiko, where a decrease by $5.1 \%$ was registered under GISS A2 2080s. Yield across all locations oscillated between 12.9 and $38.5 \%$. Projected increased CVs occurred at Bamenda, Tiko and Yaounde, with growing season becoming shorter by 2 to $5 \mathrm{~d}$.

\subsubsection{Soybean}

A substantial increase in soybean yields was generally estimated for the future. GISS and HadCM3 projected yield increases in the range from 27.9 to $153.6 \%$ in the 2020s and from 5.5 to $162.4 \%$ in the 2080s, with decreasing year-to-year variance. In Bamenda, average yield gain across all scenarios was $51.3 \%$, whereas at Ngaoundere and Tiko it was 23.0 and $141.1 \%$. HadCM3 projections resulted in more yield gains. The change in maturity dates across the areas of cultivation ranged between 5 and $23 \mathrm{~d}$ shorter.

\section{DISCUSSION AND IMPLICATIONS FOR POLICY}

The study shows that most crop yields will likely be different in the future under the effects of increased atmospheric $\mathrm{CO}_{2}$ and the resulting climatic changes, as expressed by the 8 future climate scenarios. For the future climates, maize yields are projected to decrease 
Table 6. Variation in crop yields under projected climates across agricultural regions (percent changes from base climate). Coefficient of variation $=100 \times$ standard deviation $/$ mean

\begin{tabular}{|c|c|c|c|c|c|c|c|c|}
\hline \multirow{2}{*}{ Location } & \multicolumn{4}{|c|}{ - GISS } & \multicolumn{4}{|c|}{ HadCM3 } \\
\hline & A2 2020 & A2 2080 & B2 2020 & B2 2080 & A2 2020 & A2 2080 & B2 2020 & B2 2080 \\
\hline \multicolumn{9}{|l|}{ Maize } \\
\hline Bamenda & 19.7 & 21.1 & 19.8 & 22.9 & 17.9 & 21.9 & 17.2 & 22.1 \\
\hline Batouri & 10.4 & 18.8 & 16.8 & 12.3 & 12.4 & 14.8 & 12.7 & 9.3 \\
\hline Garoua & 7.9 & 9.5 & 7.8 & 9.2 & 13.4 & 9.3 & 7.7 & 8.9 \\
\hline Kribi & 7.9 & 8.6 & 8.2 & 7.5 & 7.1 & 7.2 & 7.6 & 7.7 \\
\hline Maroua & 8.5 & 6.4 & 8.9 & 7.3 & 8.0 & 6.9 & 8.3 & 8.3 \\
\hline Ngaoundere & 4.3 & 3.5 & 5.0 & 4.3 & 4.3 & 3.8 & 4.3 & 4.3 \\
\hline Tiko & 5.2 & 5.6 & 4.9 & 5.1 & 4.7 & 5.6 & 4.7 & 5.1 \\
\hline Yaounde & 6.2 & 7.0 & 6.2 & 7.5 & 7.0 & 8.2 & 7.0 & 7.4 \\
\hline Mean & 8.8 & 10.1 & 9.7 & 9.5 & 9.4 & 9.7 & 8.7 & 9.1 \\
\hline \multicolumn{9}{|l|}{ Groundnut } \\
\hline Bamenda & 9.5 & 6.1 & 9.6 & 6.2 & 9.8 & 7.5 & 9.7 & 7.7 \\
\hline Batouri & 51.1 & 51.7 & 49.6 & 48.3 & 46.7 & 47.9 & 42.0 & 47.7 \\
\hline Garoua & 8.7 & 7.7 & 8.7 & 8.2 & 11.0 & 8.1 & 8.7 & 8.4 \\
\hline Kribi & 14.0 & 17.1 & 14.0 & 14.0 & 13.9 & 14.0 & 14.0 & 14.0 \\
\hline Maroua & 10.5 & 10.3 & 10.5 & 10.4 & 10.5 & 10.4 & 10.5 & 10.4 \\
\hline Ngaoundere & 8.4 & 10.1 & 8.5 & 9.6 & 8.3 & 9.6 & 8.2 & 9.4 \\
\hline Tiko & 28.0 & 27.8 & 27.3 & 29.3 & 26.3 & 25.9 & 25.9 & 26.1 \\
\hline Yaounde & 12.5 & 12.4 & 12.8 & 12.4 & 12.7 & 12.4 & 12.7 & 12.5 \\
\hline Mean & 17.8 & 17.9 & 17.6 & 17.3 & 17.4 & 17.0 & 16.5 & 17.0 \\
\hline \multicolumn{9}{|l|}{ Bambara } \\
\hline Bamenda & 7.3 & 21.9 & 6.9 & 7.4 & 7 & 7.7 & 7.3 & 6.9 \\
\hline Garoua & 4.3 & 4 & 4.3 & 4 & 4.6 & 4 & 4.8 & 4.1 \\
\hline Maroua & 7.5 & 7.6 & 7.5 & 7.5 & 7.7 & 7.5 & 7.7 & 7.5 \\
\hline Ngaoundere & 7 & 7.6 & 6.8 & 7.3 & 6.3 & 7.4 & 6.2 & 7.1 \\
\hline Tiko & 29.1 & 26.5 & 39.8 & 25.3 & 25.7 & 17.9 & 23.4 & 28.5 \\
\hline Yaounde & 8.3 & 8.5 & 8.2 & 8.5 & 8.9 & 8.5 & 9 & 8.4 \\
\hline Mean & 10.6 & 12.7 & 12.3 & 10.0 & 10.0 & 8.8 & 9.7 & 10.4 \\
\hline \multicolumn{9}{|l|}{ Sorghum } \\
\hline Garoua & 16.4 & 12.7 & 16.9 & 13.9 & 23.0 & 13.5 & 18.8 & 15.4 \\
\hline Maroua & 17.8 & 14.6 & 16.2 & 16.9 & 15.5 & 15.9 & 17.1 & 17.5 \\
\hline Ngaoundere & 18.7 & 19.5 & 17.9 & 20.4 & 16.6 & 18.4 & 16.7 & 31.2 \\
\hline Mean & 17.6 & 15.6 & 17.0 & 17.1 & 18.4 & 15.9 & 17.5 & 21.4 \\
\hline \multicolumn{9}{|l|}{ Soybean } \\
\hline Bamenda & 9.9 & 10.8 & 10.2 & 11.1 & 10.9 & 11.2 & 18.3 & 10.1 \\
\hline Ngaoundere & 3.8 & 5.6 & 3.5 & 4.6 & 3.5 & 4.4 & 3.5 & 4.5 \\
\hline Tiko & 33.3 & 27.5 & 32.2 & 30.3 & 23.4 & 22.1 & 28.1 & 20.4 \\
\hline Mean & 15.7 & 14.7 & 15.3 & 15.3 & 12.6 & 12.6 & 16.6 & 11.7 \\
\hline
\end{tabular}

or stay relatively unchanged; sorghum yields are projected to decrease, especially according to the GISS A2 2080 scenario; bambara groundnut, groundnut and soybean yields are projected to be substantially higher in all of the agricultural regions of Cameroon. Overall there is a clear A-OGCM model-linked pattern emerging from these results. For all crops, the more positive changes (highest increase or smallest decrease) are found when using the HadCM3 scenarios and the more negative changes are found with GISS scenarios. Of the 2 GCMs used, the GISS links increasing temperatures with decreasing rainfall, whilst the HadCM3 model forecasts an increase in temperature accompanied by increased precipitation. The differences in crop yield under each of the scenarios at each location reflect a complex interplay between temperature increase, projected changes in precipitation and increase in atmospheric $\mathrm{CO}_{2}$ concentrations. The transient GCM scenarios created in the present study provide a plausible indication of the Cameroon climate over the coming decades of the 21st century, depending on emissions of GHG and trends in energy demands.

Higher temperatures translate into faster crop development and earlier maturation, which results in lower crop yields because the plant intercepts less cumulative $S_{\mathrm{o}}$ before it reaches maturity and harvest (Brassard $\&$ Singh 2007). This relationship appears to be confirmed by the results presented, although changes in cloud patterns that may alter the atmospheric radiative transfer are not assessed here. Growing periods are shorter under GISS scenarios than under HadCM3. 

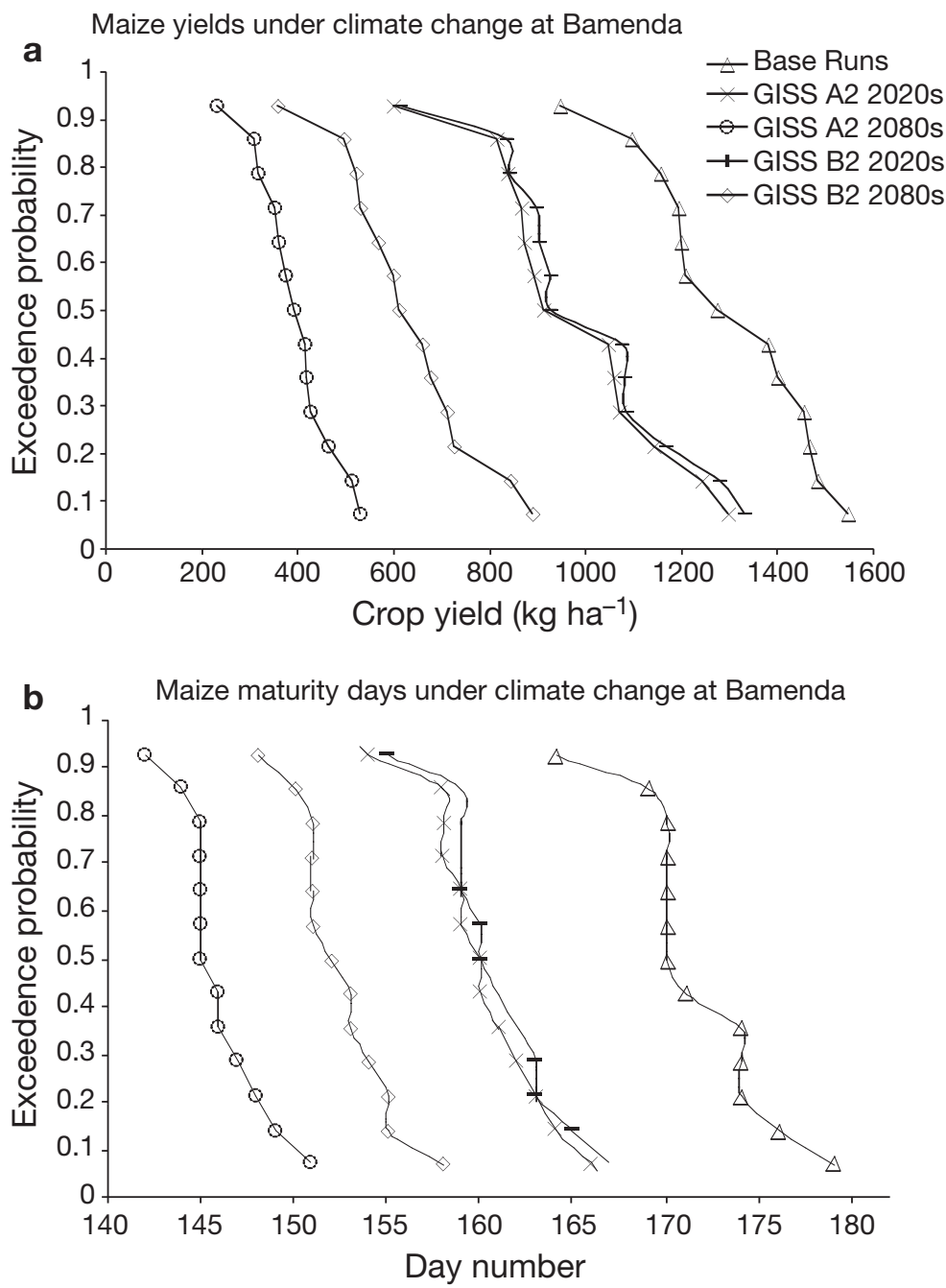

Fig. 2. Exceedence probability distribution of (a) maize grain yields under baseline and climate change scenarios and (b) maize maturity days under climate change scenarios at Bamenda

This is because the projected temperatures under HadCM3 scenarios were moderate, so little change in development period occurred as the climate changed. Under GISS climate change scenarios, high temperatures and decreased precipitation worked in unison to decrease growth period in the future projections. In addition, the increased rainfall in the HadCM3 scenarios was able to accommodate the increased growth due to enhanced photosynthesis that occurred under elevated $\mathrm{CO}_{2}$ conditions.

Using regression analysis, Rosenzweig \& Hillel (1993) found that daily $\mathrm{T}_{\max }>30^{\circ} \mathrm{C}$ during the growing season were negatively correlated with maize yield in the US Maize Belt. The future Cameroonian climate scenarios used had maximum daily temperatures $>30^{\circ} \mathrm{C}$ on several days during the growing season (Table 7). Results in this table closely match the yield changes of maize and sorghum, with an increased number of days with temperatures $>30^{\circ} \mathrm{C}$ within a given scenario resulting in decreased yields. These findings are similar to those of Chipanshi et al. (2003) and Adejuwon (2006).

The positive effects of elevated $\mathrm{CO}_{2}$ concentrations on biomass production and grain yield are higher at increased temperatures for C3 carbon-fixation plants (Wheeler et al. 1996). For Cameroon, our results indicate that the negative effect of increased temperatures will, in almost all cases for bambara groundnut, groundnut and soybean, be compensated by the positive effects of higher $\mathrm{CO}_{2}$ concentrations. The drops in the yield of groundnut and bambara at Bamenda and Tiko under the GISS and HadCM3 scenarios A2/B2 2080, respectively, may at least in part be explained by changes in nodule activity and nitrogen supply as a result of the higher temperatures and/or precipitation changes (Haskett et al. 2000).

Overall, a strong increase is projected in bambara, groundnut and soybean (C3 crops) yields and little or no change and even decreases for maize and sorghum (C4 crops). These are consistent with other simulations and experimental results reported by Downing et al. (2000) and Thomson et al. (2005). They show the greater importance of the direct $\mathrm{CO}_{2}$ fertilization effect for $\mathrm{C} 3$ species where it is responsible for most of the anticipated increases in future yields. The direct $\mathrm{CO}_{2}$ effects have less of an impact on $\mathrm{C} 4 \mathrm{crop}$ yields because these crops are already near their maximum photosynthesis rate at current $\mathrm{CO}_{2}$ levels (Chartzoulakis \& Psarras 2005).

Although the magnitude and direction of climate change effects on crop yields are dependent on the simulated strength of the $\mathrm{CO}_{2}$ response (Fig. 3), Long et al. (2006) and Morgan et al. (2005) are critical of the way in which $\mathrm{CO}_{2}$ effects on crop production are simulated, pointing out the possible exaggeration of an increased $\mathrm{CO}_{2}$ effect under controlled conditions. This is particularly relevant to $\mathrm{C} 3$ crops, in which the photosynthetic efficiency was assumed to be $>30 \%$. Long et al. (2007) argue that the actual effect of $\mathrm{CO}_{2}$ concentration is about half of that suggested by experiments used to develop climate models. In the same way, Leakey et al. (2006) showed that maize crops growing under ample water and nutrients showed a lack of response to increased $\mathrm{CO}_{2}$. Following Leakey et al. (2006) and Long et al. (2007), then, the pattern of modelled agricultural yields in Cameroon shown here may 
Table 7. Average number of days in the growing season with maximum daily temperature $>30^{\circ} \mathrm{C}$ under current climate (baseline) and climate change scenarios projected by 2 climate change models (GISS and HadCM3) for 2 future decades (2020 and 2080)

\begin{tabular}{|c|c|c|c|c|c|c|c|c|c|}
\hline \multirow{2}{*}{ Location } & \multirow{2}{*}{ Baseline } & \multicolumn{4}{|c|}{$\longrightarrow$ GISS- } & \multicolumn{4}{|c|}{ HadCM3 } \\
\hline & & A2 2020 & A2 2080 & B2 2020 & B2 2080 & A2 2020 & A2 2080 & B2 2020 & B2 2080 \\
\hline Bamenda & 5 & 15 & 52 & 14 & 30 & 9 & 35 & 8 & 22 \\
\hline Batouri & 60 & 89 & 133 & 87 & 113 & 75 & 123 & 75 & 107 \\
\hline Garoua & 110 & 134 & 154 & 132 & 147 & 120 & 147 & 121 & 140 \\
\hline Kribi & 83 & 113 & 147 & 111 & 135 & 98 & 139 & 97 & 127 \\
\hline Maroua & 109 & 131 & 150 & 129 & 145 & 117 & 144 & 118 & 137 \\
\hline Ngaoundere & 17 & 37 & 92 & 35 & 64 & 24 & 69 & 25 & 50 \\
\hline Tiko & 81 & 109 & 142 & 107 & 128 & 95 & 134 & 95 & 120 \\
\hline Yaounde & 36 & 62 & 113 & 60 & 87 & 48 & 101 & 48 & 80 \\
\hline
\end{tabular}

be incorrectly biased towards a positive response. Such uncertainty about the response of crops to atmospheric $\mathrm{CO}_{2}$ concentrations raises doubts on the ability to model future yields. Locations with modelled increases might see no change, and those with no change or reductions might in reality experience crop failure. On the other hand, Ewert et al. (2007) and Tubiello et al. (2007) showed that crop yield responses to elevated $\mathrm{CO}_{2}$ are similar across FACE (free air carbon enrichment) and non-FACE experimental data.
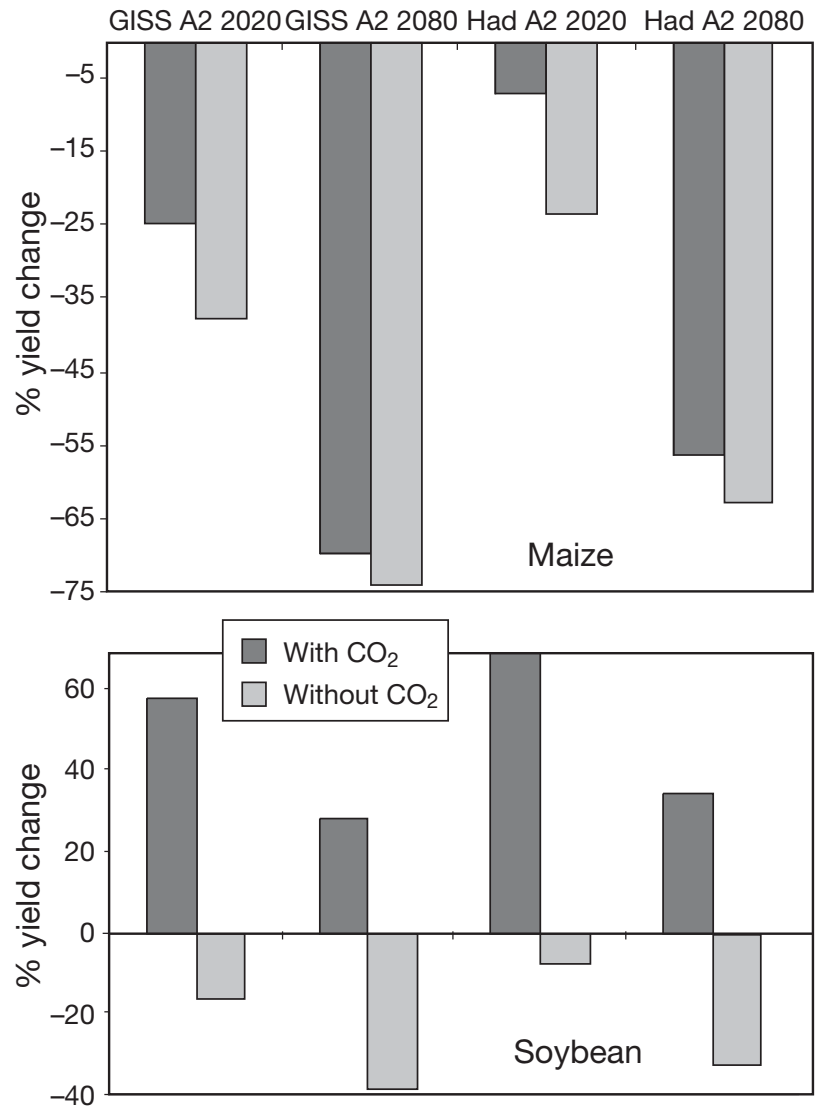

Fig. 3. Changes in simulated yields of maize and soybean (Bamenda station) in response to climate change with/without accounting for the direct effect of atmospheric $\mathrm{CO}_{2}$
Their results conflict with those of Long et al. (2007), and they urge greater co-operation between experimentalists and modellers across all disciplines, so that key questions of importance to crop yield and crop production under future climate, environmental and socio-economic change can be framed within comprehensive and mutually beneficial research programmes.

Uncertainties in the response of crops to elevated $\mathrm{CO}_{2}$ also have to be related to the uncertainty associated with limitations of the climate change projections and how they manifest themselves in crop model estimates. In the present study, coarse-scale GCM data have been used and $S_{\mathrm{o}}$ has been estimated by CropSyst. It was beyond the scope of this study (and the capabilities of the data used) to investigate what the changing relationships between altered precipitation and temperature magnitudes and $S_{0}$ might be in the future. Using CropSyst to estimate $S_{\mathrm{o}}$ for all scenarios partially resolves the issue of the relationship between temperature and $S_{0}$, but not precipitation and $S_{0}$. The future projection data are based on magnitude adjustments of the current climate; hence, in reality, future correlations between variables will change, but this is not encompassed within the data. Further downscaling sophistication is required in order to supply more reliable, site representative data that include relative changes between temperature, cloud cover, precipitation and $S_{0}$.

Clearly, climate change will also have complex interaction with the timing and severity of disease, pest and weed interactions (Fuhrer 2003), but their combined effects on the yields presented here were assumed to be controlled. This sends a cautious signal to Cameroon where poor and vulnerable people are dependent on agriculture and failure in crop production under climate change will exacerbate poverty and food-insecurity challenges already faced by an impoverished rural and urban society.

Also, the projected climate had mixed effects on variation of yields as shown in Table 6. The construction of GCM scenarios assumes that the climate vari- 
ability of the future is the same as the observed; therefore, any changes in the $\mathrm{CV}$ of yields were as a result of a complex mix of temperature, rainfall, $\mathrm{CO}_{2}$ fertilization effect and plant physiology, interacting with soil properties and affecting crop growth over time (Thomson et al. 2005, Alcamo et al. 2007). In reality the projected climate change will result in higher yield variability, posing significant consequences for farming businesses and future management decisions (Mearns et al. 1997, Tingem et al. 2008). Thus, predicting seasonal rainfall and yield will become more important than for the current climate, and farmers will need to make more dynamic and tactical decisions about crop choices. On the side of public authorities, more effective extension programs are needed to bring about or increase farmers' awareness of climate change. More effective farm planning, crop insurance and economic diversification offer the potential of increasing farmers' resilience to adverse changes in the future.

The simulations showed, especially for maize and sorghum, a different type of adaptation to climate change is needed. One of the effects of higher temperature in Cameroon is reduced growth and grain filling periods. Developing different cultivars, which are better adapted to future climates is one option, especially varieties with a longer season. Other potential adaptations include changes in sowing date, the implications of which the authors are currently researching. Some locations may be suitable for development of water storage and irrigation capabilities, but these will require substantial infrastructural and educational investments. Increased incidence of supra-optimal temperatures will make larger areas of Cameroon unsuitable for maize and sorghum cultivation, perhaps necessitating a return to bambara groundnut, groundnut and soybean, which may be critical in ensuring food security in an uncertain future. Indeed, this will have important social implications because maize and sorghum have become cultural symbols for people in this region. This will require a lot of interdisciplinary research work in order to find acceptable substitute food crops.

However, the conclusions and recommendations presented here must not be seen as accurate predictions of future crop yields, but more as indicators of the possible impacts of climate change on Cameroon's agriculture, which may be useful in designing appropriate adaptation options. It is the responsibility of the government and the scientific community to provide farmers with the adequate and necessary expertise and guidance for undertaking proactive, wellinformed adaptation measures. Also, more improvement in the amount of available data and rigorous field experimentation, which could enhance our ability to assess the impacts of future climate scenarios on cropping systems dynamics, are needed.
Acknowledgements. We acknowledge the help and assistance provided by C. O. Stöckle and R. L. Nelson (Biological Systems Engineering Department, Pullman, WA, USA) in using CropSyst and ClimGen. Climate change scenarios were provided by the NASA/Goddard Institute for Space Studies (New York), thanks to R. Goldberg and C. Rosenzweig.

\section{LITERATURE CITED}

Abraha MG, Savage MJ (2006) Potential impacts of climate change on the grain yield of maize for the midlands of KwaZulu-Natal, South Africa. Agric Ecosyst Environ 115: $150-160$

Adejuwon JO (2006) Food crop production in Nigeria. II. Potential effects of climate change. Clim Res 32:229-245

Agristat (2001) Semi-annual bulletin of the statistics of agricultural sector 200/2001. DEPA, Ministry of Agriculture, Yaounde, Cameroon

Alcamo J, Dronin N, Endejan M, Golubev G, Kirilenko A (2007) A new assessment of climate change impacts on food production shortfalls and water availability in Russia. Glob Environ Change 17:429-444

ANL (Agronne National Laboratory) (1994) Guidance for vulnerability and adaptation assessment. US Country Studies Program, Washington, DC

Batjes N (1995) A homogenised soil data file for global environmental research: a subset of FAO, ISRIC and NRCS profiles (Version 1.0). Working paper 95/10. International Soil Reference Information Center (ISRIC), Wageningen

Boko M, Niang I, Nyong A, Vogel A and others (2007) Africa: climate change 2007: impacts, adaptation and vulnerability. In: Parry ML, Palutikof OF, Van der Linden PJ, Hanson CE (eds) Contribution of Working Group II to the 4th assessment report of the Intergovernmental Panel on Climate Change. Cambridge University Press, Cambridge, p 433-467

Brassard JE (2003) Valuation des impacts de la hausse de la concentration atmosphérique du $\mathrm{CO}_{2}$ et des changements climatiques sur la production agricole du Québec. Mémoire de Maitrise, Département de Géographie, Université de Montréal, Montreal

Brassard J, Singh B (2008) Impacts of climate change and $\mathrm{CO}_{2}$ increase on agricultural production and adaptation options for southern Québec, Canada. Mitig Adapt Strateg Glob Change 13:241-265

Chartzoulakis K, Psarras G (2005) Global change effects on crop photosynthesis and production in Mediterranean: the case of Crete, Greece. Agric Ecosyst Environ 106:147-157

Chipanshi AC, Chanda R, Totolo O (2003) Vulnerability assessment of the maize and sorghum crops to climate change in Botswana. Clim Change 61:339-360

Christensen JH, Hewitson BC, Busuioc A, Chen A and others (2007) Regional climate projections. Climate change 2007: the physical science basis. In: Solomon S, Qin D, Manning M, Chen Z and others (eds) Contribution of Working Group I to the 4th assessment report of the Intergovernmental Panel on Climate Change. Cambridge University Press, Cambridge, p 847-940

CIA (Central Intelligence Agency) (2007) World fact book (Cameroon). Available at https://www.cia.gov/library/ publications/the-world factbook/geos/cm (accessed on 9 August 2007)

Downing TE, Harrison PA, Butterfield RE, Lonsdale KG (eds) (2000) Climate change, climatic variability and agriculture in Europe. An integrated assessment. Research Report No. 
21. Contract ENV4-CT95-0154, Commission of the European Union, Brussels

Ewert F, Porter JR, Rounsevell MDA (2007) Crop models, $\mathrm{CO}_{2}$ and climate change. Science 315:459

Farre I (1998) Maize (Zea mays L.) and sorghum (Sorghum bicolor L. Moench) response to deficit irrigation. Agronomy and modelling. PhD dissertation, University of Lieida

Fuhrer J (2003) Agroecosystem responses to combinations of elevated $\mathrm{CO}_{2}$, ozone and global climate change. Agric Ecosyst Environ 97:1-20

Hansen JE, Sato MKI, Lacis A, Ruedy R, Tegen I, Matthews E (1998) Perspective: climate forcing in the industrial era. Proc Natl Acad Sci USA 95:12753-12758

Haskett JD, Pashepsky YA, Acock B (2000) Effect of climate and atmospheric change on soybean water stress: a study of Iowa. Ecol Modell 135:265-277

Houghton J, Ding Y, Griggs DJ, Noguer M, van der Linden PJ, Xiaosu D (2001) Climate change 2001: the scientific basis. Contribution of Working Group I to the 3rd assessment report of the Intergovernmental Panel on Climate Change. Cambridge University Press, Cambridge

Johns TC, Gregory JM, Ingram CE, Johnson CE and others (2003) Anthropogenic climate change for 1860-2100 simulated with the HadCM3 model under updated emissions scenarios. Clim Dyn 20:583-612

Kabubo-Mariara J, Karanja FK (2007) The economic impact of climate change on Kenyan crop agriculture: a Ricardian approach. Global Planet Change 57:319-330

Kurukulasuriya P, Mendelsohn R, Hassan R (2006) Will African agriculture survive climate change? World Bank Econ Rev 20:367-388

Leakey ADB, Uribelarrea M, Ainsworth EA, Naidu SL, Rogers A, Ort DR (2006) Photosynthesis, productivity, and yield of maize are not affected by open-air elevation of $\mathrm{CO}_{2}$ concentration in the absence of drought. Plant Physiol 140: 779-790

Long SP, Ainsworth EA, Leakey ADB, Nosberger J, Ort DR (2006) Food for thought: lower-than-expected crop yield stimulation with rising $\mathrm{CO}_{2}$ concentrations. Science 312: 1918-1921

Long SP, Ainsworth EA, Leakey ADB, Ort DR, Nosberger J, Schimel D (2007) Crop models, $\mathrm{CO}_{2}$ and climate change. Science 315:459-460

Mearns LO, Rosenzweig C, Goldberg R (1997) Mean and variance change in climate scenarios: methods, agricultural applications and measures of uncertainty. Clim Change 35:367-396

Molua EL, Utomakili JB (1998) An analysis of resource-use efficiency in banana production in the south west province of Cameroon. Int J Trop Agric 16:113-118

Morgan PB, Bollero GA, Nelson RL, Dohleman FG, Long SP (2005) Smaller than predicted increase in above-ground net primary production and yield of field-grown soybean was found when $\left[\mathrm{CO}_{2}\right]$ is elevated in fully open-air. Glob Change Biol 11:1856-1865

Moriondo M, Maselli F, Bindi M (2007) A simple model of regional wheat yield based on NDVI data. Eur J Agron 26:266-274

Ndemah RN (1999) Towards an integrated crop management strategy for the African stalk borer Busseola fusca (Fuller) (Lepidoptera: Noctuidae) in maize systems in Cameroon. PhD thesis, University of Hannover

Priestley CHB, Taylor RJ (1972) On the assessment of surface heat flux and evaporation using large-scale parameters. Mon Weather Rev 100:81-82

Richardson CW (2000) Data requirement for estimation of weather generation parameters. Trans Am Soc Agric Eng 43:877-882

Ritchie JT, Singh U, Godwin DC, Bowen WT (1998) Cereal growth, development and yield. In: Tsuji GY, Hoogenboom G, Thornton PK (eds) Understanding options for agricultural production. Kluwer Academic, Dordrecht, p 79-98

Rivington M, Bellocchi G, Matthews KB, Buchan K (2005) Evaluation of three model estimates of solar radiation at 24 UK stations. Agric For Meteorol 132:228-243

Rivington M, Matthews KB, Bellocchi G, Buchan K, Stöckle CO, Donatelli M (2007) An integrated assessment approach to conduct analyses of climate change impacts on whole-farm systems. Environ Model Softw 22:202-210

Rosenzweig C, Hillel D (1993) Agriculture in a greenhouse world. National Geographic Research and Exploration 9:201-221

Rosenzweig C, Tubiello FN (1997) Impacts of future climate change on Mediterranean agriculture: current methodologies and future directions. Mitig Adapt Strateg Glob Change 1:219-232

Rosenzweig C, Tubiello FN (2007) Adaptation and mitigation strategies in agriculture: an analysis of potential synergies. Mitig Adapt Strateg Glob Change 12:855-873

Seo SN, Mendelsohn R, Munasinghe M (2005) Climate change and agriculture in Sri Lanka. Environ Dev Econ 10:581-596

Slingo JM, Challinor AJ, Hiskin BJ, Wheeler TR (2005) Introduction: food crops in a changing climate. Philos Trans $\mathrm{R}$ Soc Lond B Biol Sci 360:1983-1989

Stöckle CO, Donatelli M, Nelson R (2003) CropSyst, a cropping systems simulation model. Eur J Agron 18:289-307

Thomson AM, Rosenberg NJ, Izaurralde RC, Brown RA, Benson V (2005) Climate change impacts for the conterminous USA: an integrated assessment. Part 3: dryland of grain and forage crops. Clim Change 69:43-65

Thornton PK, Jones PG, Owiyo TM, Kruska RL and others (2006) Mapping climate vulnerability and poverty in Africa. Report to the Department for International Development, ILRI, Nairobi

Tingem M, Rivington M, Azam Ali SN, Colls JJ (2007) Assessment of the ClimGen stochastic weather generator at Cameroon sites. Afr J Environ Sci Technol 1:86-92

Tingem M, Rivington M, Azam-Ali SN, Colls JJ (2008) Climate variability and maize production in Cameroon: simulating the effects of extreme dry and wet years. Singap J Trop Geogr (in press)

Tubiello FN, Donatelli M, Rosenzweig C, Stöckle CO (2000) Effects of climate change and elevated $\mathrm{CO}_{2}$ on cropping systems: model predictions at two Italian locations. Eur J Agron 13:179-189

Tubiello FN, Amthor JS, Boote KJ, Donatelli $\mathrm{M}$ and others (2007) Crop response to elevated $\mathrm{CO}_{2}$ and world food supply: a comment on 'Food for Thought...' by Long et al. Science 312:1918-1921, 2006. Eur J Agron 26:215-223

USCP (US Country Studies Program) (1994) Guidance for vulnerability and adaptation assessment, Version 1.0. USCP, Washington, DC

Weibull W (1961) Fatigue testing and analysis of results. Pergamon Press, Oxford

Wheeler TR, Hong TD, Ellis RH, Batts GR, Morison JIL, Hadley $\mathrm{P}$ (1996) The duration and rate of grain growth and harvest index, of wheat in response to temperature and $\mathrm{CO}_{2}$. J Exp Bot 47:623-630

World Bank (2007) World development indicators database. Available at http://devdata.worldbank.org/ (accessed on 24 July 2007)

Submitted: September 20, 2007; Accepted: December 21, 2007 Proofs received from author(s): March 4, 2008 